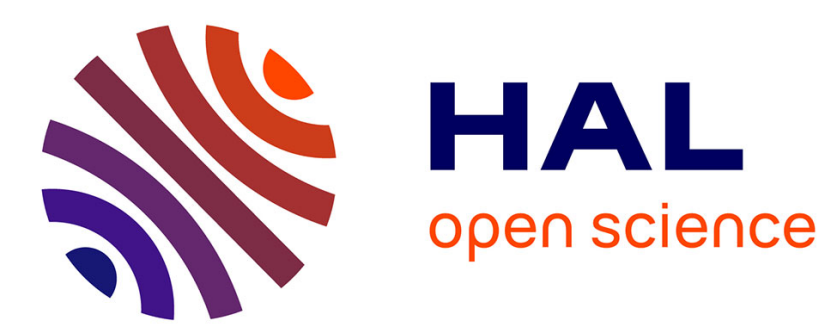

\title{
Hexagonal Si-Ge class of semiconducting alloys prepared using pressure and temperature
}

George Serghiou, Nicholas Odling, Hans Josef J Reichmann, G Ji, Monika Koch-müller, Daniel J Frost, Jonathan P Wright, Reinhard Boehler, Wolfgang Morgenroth

\section{To cite this version:}

George Serghiou, Nicholas Odling, Hans Josef J Reichmann, G Ji, Monika Koch-müller, et al.. Hexagonal Si-Ge class of semiconducting alloys prepared using pressure and temperature. Chemistry - A European Journal, 2021, 10.1002/chem.202102595 . hal-03379143

\section{HAL Id: hal-03379143 https://hal.science/hal-03379143}

Submitted on 14 Oct 2021

HAL is a multi-disciplinary open access archive for the deposit and dissemination of scientific research documents, whether they are published or not. The documents may come from teaching and research institutions in France or abroad, or from public or private research centers.
L'archive ouverte pluridisciplinaire HAL, est destinée au dépôt et à la diffusion de documents scientifiques de niveau recherche, publiés ou non, émanant des établissements d'enseignement et de recherche français ou étrangers, des laboratoires publics ou privés. 


\title{
Hexagonal Si-Ge class of semiconducting alloys prepared using pressure and temperature
}

\author{
George Serghiou, ${ }^{*[a]}$ Nicholas Odling, ${ }^{[b]}$ Hans Josef Reichmann, ${ }^{[c]}$ Gang Ji, ${ }^{[d]}$ Monika Koch-Müller, ${ }^{[c]}$ \\ Daniel J. Frost, ${ }^{[\mathrm{e}]}$ Jonathan P. Wright, ${ }^{[f]}$ Reinhard Boehler ${ }^{[g]}$ and Wolfgang Morgenroth ${ }^{[\mathrm{h}, \mathrm{i}, \mathrm{j}]}$
}

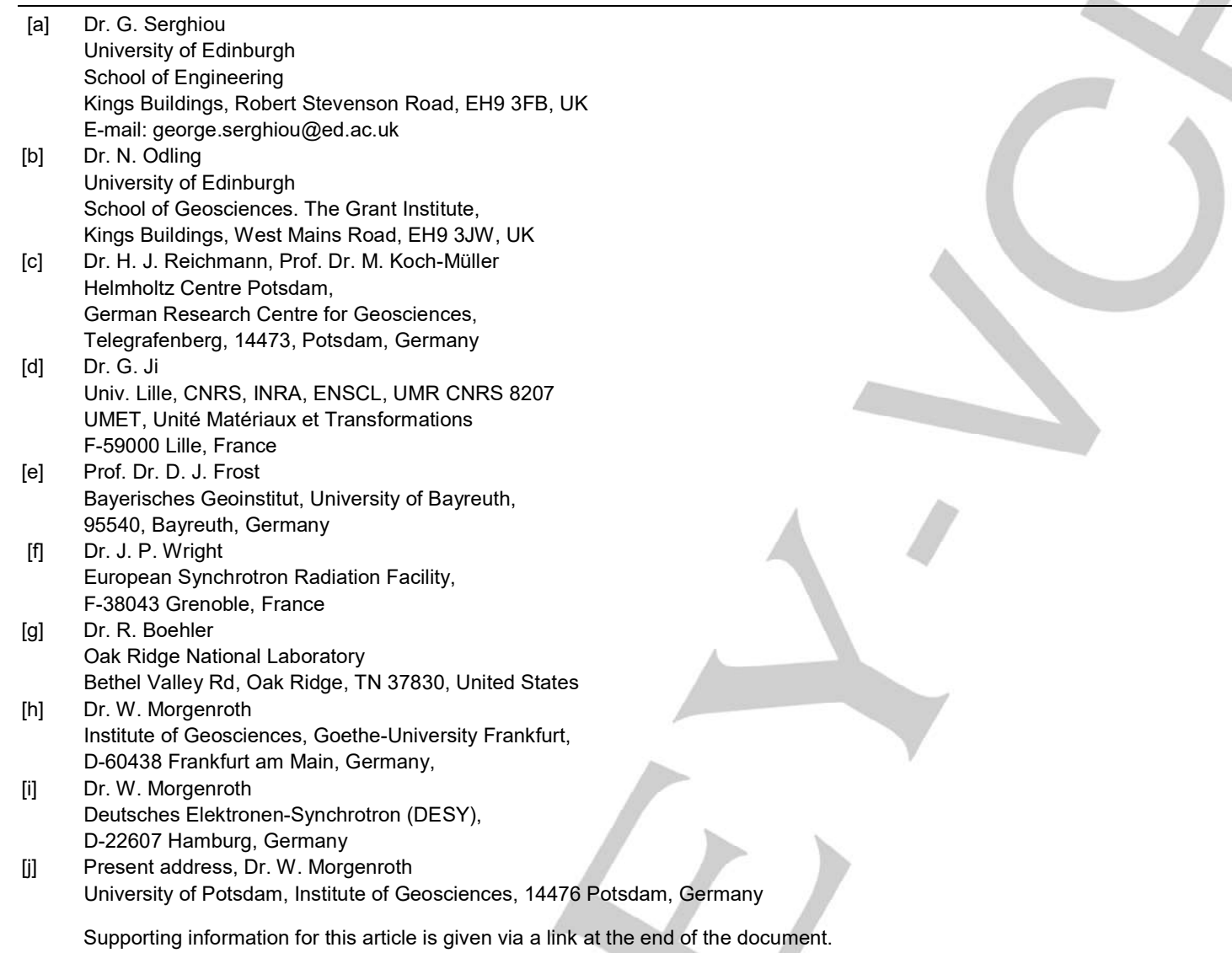

\begin{abstract}
Multi-anvil and laser-heated diamond anvil methods are used to subject $\mathrm{Ge}$ and $\mathrm{Si}$ mixtures to pressures and temperatures of between 12 and $17 \mathrm{GPa}$ and $1500-1800 \mathrm{~K}$, respectively. Synchrotron angle dispersive $\mathrm{X}$-ray diffraction, precession electron diffraction and chemical analysis using electron microscopy, reveal recovery at ambient pressure of hexagonal $\mathrm{Ge}-\mathrm{Si}$ solid solutions $\left(P 6_{3} / m m c\right)$. Taken together, the multi-anvil and diamond anvil results reveal that hexagonal solid solutions can be prepared for all $\mathrm{Ge}-\mathrm{Si}$ compositions. This hexagonal class of solid solutions constitutes a significant expansion of the bulk Ge-Si solid solution family, and is of active interest for optoelectronic applications.
\end{abstract}

\section{Introduction}

Cubic diamond ( $\mathrm{Si}, \mathrm{Ge}$ )-based technology is fundamental to the microelectronics industry. The strong drive to transfer this dominance to optoelectronics is however hampered by the fact that cubic diamond- structured silicon, germanium and their solid solutions inherently all exhibit indirect band-gaps making them inefficient for photovoltaic and light emitting applications. ${ }^{[1]}$ Our approach, rather than try to process $\mathrm{Si}-\mathrm{Ge}$ within the existing cubic Si-Ge diamond crystal symmetry to remedy these constraints, ${ }^{[2]}$ change the crystal symmetry instead into new ones that inherently exhibit targeted properties. That is, develop new group IV materials landscapes by exploring synthesis of new structures which intrinsically contain tunable properties including fundamental direct band-gaps.

To do this we target regions of the pressure-temperature phase diagram of the reactant group IV elements where different crystal structures than ambient are accessible (Figure 1)..$^{[5]} \mathrm{We}$ first employed this approach in a group IV system for Ge-Sn, also of pronounced current interest. ${ }^{[6-10]}$ We namely made unreactive $\mathrm{Ge}$ and $\mathrm{Sn}$, reactive in the bulk by heating them at 10 $\mathrm{GPa}$, leading to recovery at ambient conditions of a novel tetragonal Ge-Sn solid solution $\left(P 4_{3} 2_{1} 2\right) \cdot{ }^{[8-10]}$ In the Si-Ge system we recovered to ambient conditions two new solid solution crystal symmetries, a cubic $(l a \overline{3})$ and a tetragonal one $\left(P 4_{3} 2_{1} 2\right)$, after heating $\mathrm{Ge}$ and $\mathrm{Si}$ at between $12-17 \mathrm{GPa} .{ }^{[11]}$ Single crystal precession electron diffraction documented the cubic ( la $\overline{3}$ ) crystal symmetry for compositions down to 24 at\% Si and $\left(P 4_{3} 2{ }_{1} 2\right)$ for lower Si concentrations. The cubic $(l a \overline{3})$ symmetry was also documented via clear angle dispersive $\mathrm{X}$-ray diffraction patterns for a bulk $\mathrm{Si}_{0.8} \mathrm{Ge}_{0.2}$ composition but X-ray diffraction 


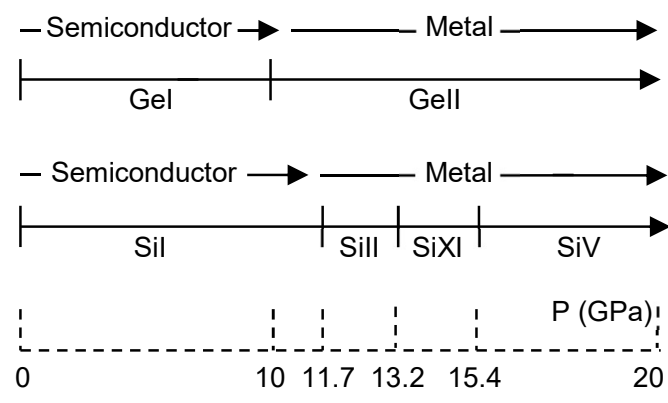

a

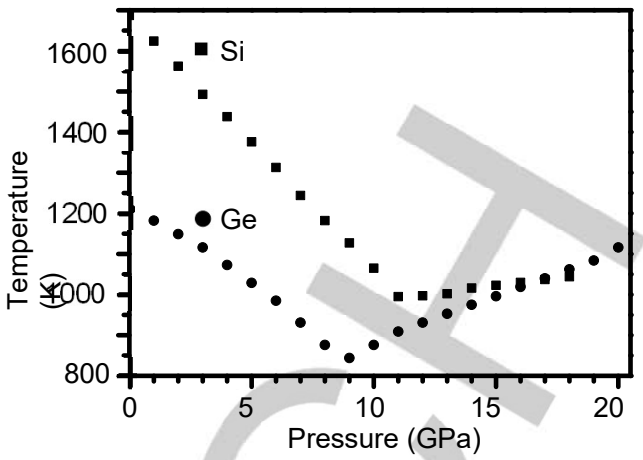

b

Figure 1. Phase relations and structural characteristics of $\mathrm{Ge}$ and $\mathrm{Si}$ as a function of pressure and temperature. (a) Gel (cubic diamond structure, Fd $\overline{3} m$ ) transforms to metallic Gell ( $\beta$-Sn structure, $14_{1} / a m d$ ) above $9 \mathrm{GPa}$. Sil (cubic diamond structure $F d \overline{3} m$ ) transforms to metallic Sill ( $\beta$-Sn structure, $14{ }_{1} / a m d$ ) above $11 \mathrm{GPa}$. Above $13 \mathrm{GPa}$, this transforms to an orthorhombic modification $(I \mathrm{mma})$, SiXI, and then to a hexagonal modification $\left(P_{6} / \mathrm{mmm}\right)$, SiV, above 15 $\mathrm{GPa}^{\left[{ }^{[3]}\right.}$ (b) Pressure dependency of the melting points of $\mathrm{Ge}$ and $\mathrm{Si}^{[4]}$

measurements for higher Ge compositions indicated the presence of additional bulk hexagonal Ge-Si solid solutions. ${ }^{[11]}$

The existence of bulk hexagonal solid solutions from synthesis at the above conditions, and the reason such a class of tunable novel solid solution would be technologically important, is underpinned first by a host of experiments and calculations on endmember $\mathrm{Si}$ and $\mathrm{Ge} \cdot{ }^{[12-26]} \mathrm{A}$ hexagonal phase $\left(P 6_{3} / m m c\right)^{[21-22]}$ for both $\mathrm{Ge}$ and $\mathrm{Si}$ has been reported upon recovery from above $10 \mathrm{GPa}$. The hexagonal modification forms from $\mathrm{Ge}$ and $\mathrm{Si}$ in a second step after initial recovery of the two in the cubic modification ( $l a \overline{3}$ ). Namely, Ge with $P 6_{3} / m m c$ symmetry forms from $\mathrm{Ge}$ with la $\overline{3}$ symmetry easily at room temperature, and $\mathrm{Si}$ with $P 6_{3} / \mathrm{mmc}$ symmetry from $\mathrm{Si}$ with $l a \overline{3}$ symmetry upon heating this phase. For $\mathrm{Si}, l \mathrm{a} \overline{3}$ is the ubiquitous recovered from above $10 \mathrm{GPa}$, regardless of processing conditions, whereas for $\mathrm{Ge}$, amorphous starting material, rapid pressure quenching or hydrostatic conditions are required, else the $P 4_{3} 2_{1} 2$ symmetry is recovered from above $10 \mathrm{GPa} .^{[22,27-30]}$

The intriguing technological promise of combining $\mathrm{Ge}$ and $\mathrm{Si}$ in a new class of hexagonal Ge-Si solid solutions $\left(\mathrm{P}_{3} / \mathrm{mmc}\right)$ stems from the following. Hexagonal $G e$ has a fundamental direct band-gap. ${ }^{[12,13,15,16]}$ Hexagonal $\mathrm{Si}$, while exhibiting an indirect band-gap, has a remarkable thermal stability to above $1000 \mathrm{~K}$ before it transforms back to the conventional cubic

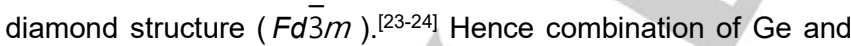
$\mathrm{Si}$ in their hexagonal modification, can be formidable, $\mathrm{Ge}$ imparting direct band-gap character and $\mathrm{Si}$ imparting enhanced thermal stability to the solid solution as exemplified also by the production of $\mathrm{SiGe}$ nanowires templated on GaAs nanowire cores. ${ }^{[31]}$ Moreover tunability of properties is achieved not only by the more conventional variation of composition, but also by the polytypic character of the hexagonal symmetry. Saliently, it is well established that the band-gap of the endmember hexagonal structure can be tuned as a function of the polytypic stacking sequence, with the band-gap increasing in going from the $2 \mathrm{H}$ to the $6 \mathrm{H}$ hexagonal polytype. ${ }^{[32-34]}$

Our bulk synthesis methods at between 12 to $17 \mathrm{GPa}$ and up to about $1800 \mathrm{~K}$ incorporated large volume multi-anvil and laserheated diamond anvil methods. The latter, employing an argon pressure medium, was also used to examine the effect of hydrostaticity on the structure of the recovered reaction products.
These extreme conditions synthetic methods are coupled with precession electron diffraction (PED) and synchrotron angle dispersive X-ray diffraction (ADX) for structural analysis, and fluorescence and electron microscopy (EM) for chemical and morphological analysis. The combination of these characterization methods is formidable for analysis of extreme conditions recovered reaction products. ${ }^{[11,35]}$ They combine namely high spatial resolution single crystal analysis with kinematic intensities (PED), high angular resolution bulk powder structural analysis (ADX), on-site synchrotron chemical fingerprinting using a fluorescence detector and high spatial resolution chemical and morphological mapping (EM).

\section{Results}

PED analysis of numerous single crystallites with accompanying chemical analysis from each analyzed crystallite from the recovered products allowed us to develop a structure composition - conditions of synthesis map of the reaction products, expanding that of the $l a \overline{3}$ and $P 4_{3} 2{ }_{1} 2$ Si-Ge landscape. ${ }^{[11]}$ We present examples below of PED patterns from multi-anvil and diamond anvil cell recovered products, followed by examples of our chemical analyses of recovered crystals from syntheses using both methods, and finally $\mathrm{X}$-ray diffraction patterns from bulk Ge-Si compositions extracted from pellets recovered from the multi-anvil experiments. Figure 2 shows zone-axis PED diffraction patterns from multi-anvil recovered Ge-Si crystallites exhibiting $P 6_{3} / m m c$ symmetry of the $4 \mathrm{H}$ polytype (Figures 2a, c) together with their simulated diffraction patterns (Figures $2 b, d$ ) revealing an excellent match with the experimental data. Figure 3 shows zone-axis PED diffraction patterns from diamond anvil recovered $\mathrm{Ge}-\mathrm{Si}$ crystallites exhibiting $P 6_{3} / m m c$ symmetry of $2 \mathrm{H}$ and $4 \mathrm{H}$ polytypes (Figures $3 a, c)$ together with their simulated diffraction patterns (Figures $3 \mathrm{~b}, \mathrm{~d})$ revealing an excellent match with the experimental data. Pattern $3 c$ was likely from a crystal whose initial structure was changed by heating in the electron beam. Examples of chemical analyses taken from the crystallites are shown in Figures 4a-d. A stackplot of X-ray diffraction patterns taken from (Ge:Si 76:24 $15 \mathrm{GPa}, 48: 52$ - $12 \mathrm{GPa}, 22: 78$ - $12 \mathrm{GPa}$ ) bulk Ge:Si 


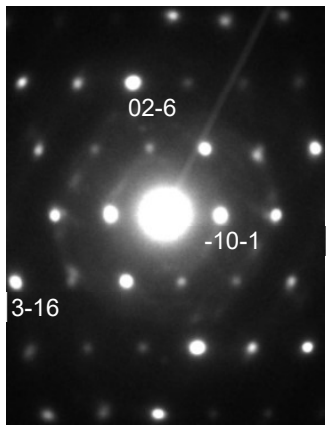

a

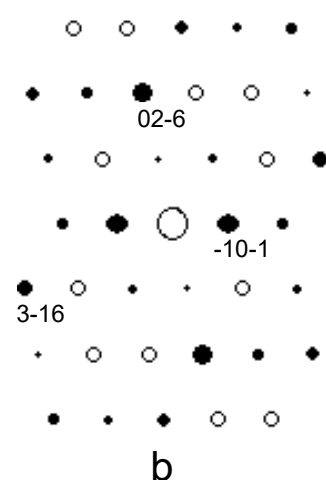

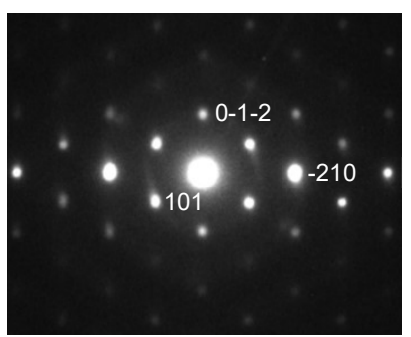

C

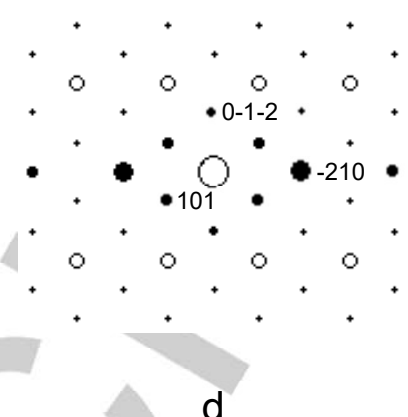

Figure 2. Experimental PED and simulated zone-axis diffraction patterns of binary Ge-Si crystals from multi-anvil syntheses with $P 66_{3} / m m c$ space group of $4 \mathrm{H}$ polytype. $(a, b)$ are experimental and simulated zone-axis diffraction patterns of the [1-3-1] zone axis and (c, d) correspondingly, of the [-1-21] zone-axis.

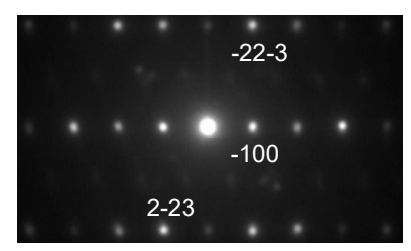

a

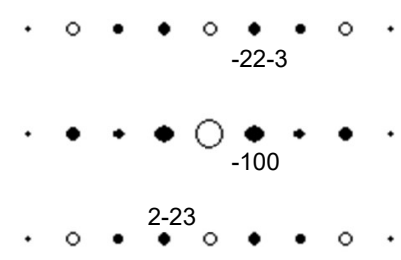

b

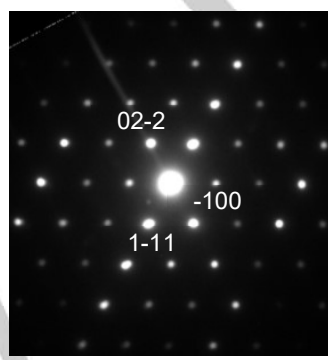

C

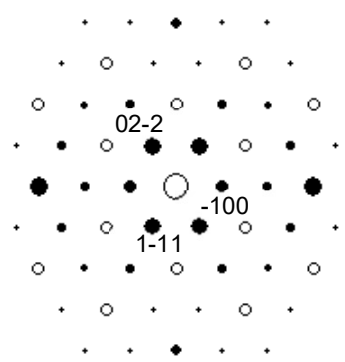

d

Figure 3. Experimental PED and simulated zone-axis diffraction patterns of binary Ge-Si crystals from laser-heated diamond anvil cell syntheses with $P 6_{3} / m m c$ space group of $2 \mathrm{H}$ and $4 \mathrm{H}$ polytype respectively. $(\mathrm{a}, \mathrm{b})$ are experimental and simulated zone-axis diffraction patterns of the [0-3-2] zone axis and (c, d) correspondingly, of the [0-1-1] zone-axis. The latter is likely a result of heating by the electron beam.

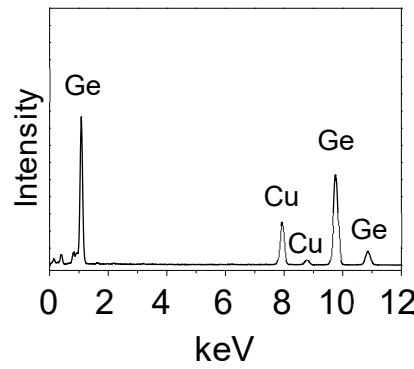

a

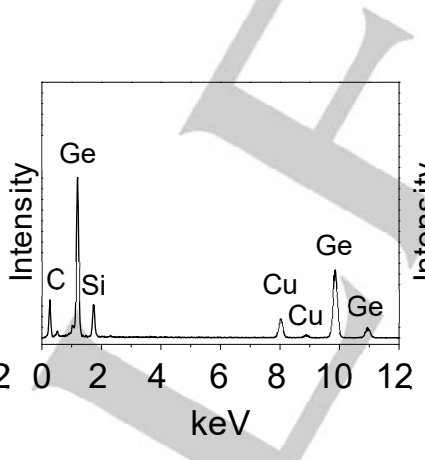

b

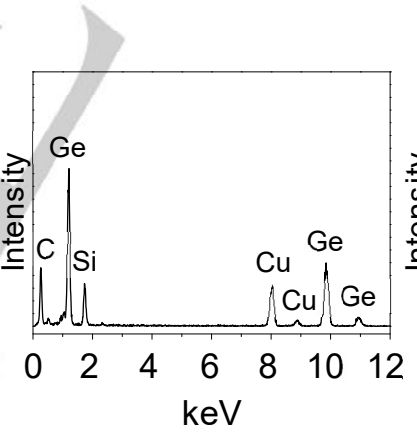

c

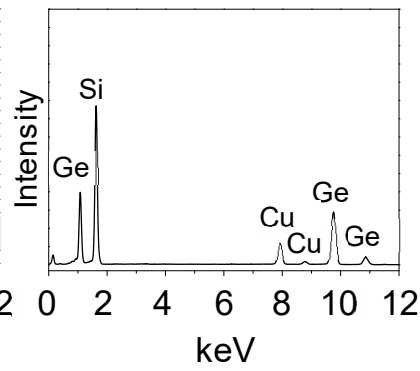

d

Figure 4. Examples of TEM/EDX chemical analysis from Ge-Si crystals with $P 6_{3} / m m c$ space group transformed from the la $\overline{3}$ symmetry after recovery from high pressure and temperature syntheses. Semi-quantitative energy dispersive X-ray analysis from four such crystals (a) $\mathrm{Ge}_{\text {, }}$ (b) $\mathrm{Ge}_{0.81} \mathrm{Si}_{0.19}$, (c) $\mathrm{Ge}_{0.78} \mathrm{Si}_{0.22}$ and (d) $\mathrm{Ge}_{0.28} \mathrm{Si}_{0.72}$ stoichiometries respectively. The $\mathrm{Cu}$ and $\mathrm{C}$ peaks originate respectively from the copper grid and carbon film of the TEM sample holder.

compositions based on chemical analysis using scanning electron microscopy, is shown in Figure 5. The results reveal[ ${ }^{[36]}$ predominant hexagonal $P 6_{3} / m m c$ structural symmetries up to bulk 76:24 composition, residual hexagonal $P 6_{3} / m m c$ at $48: 52$ composition coexisting with the predominant $l a \overline{3}$ cubic symmetry and finally at bulk $22: 78$ only the $l a \overline{3}$ structural symmetry is present. ${ }^{[11,22,28-29,34,37]}$ Rietveld refinement of five recovered reaction product diffraction patterns, further presentation of bulk compositions as well as backscattered electron microscopy images of recovered $\mathrm{Ge}-\mathrm{Si}$ reaction products are shown in the supporting information. ${ }^{[36]}$

All together based on the current work on endmember $\mathrm{Ge}$ and $\mathrm{Ge}-\mathrm{Si}$ compositions and prior work on endmembers $\mathrm{Ge}$ and $\mathrm{Si},{ }^{[21-22,26,30]}$ the hexagonal structural symmetry can be recovered, without further heating at ambient pressure, from hydrostatic decompression for $\mathrm{Ge}_{1-\mathrm{x}} \mathrm{Si}_{\mathrm{x}}$ of about $(0<\mathrm{x}<0.24)$, and under less hydrostatic decompression for compositions of about $(0.15<x<0.24)$. With further heating at ambient pressure the 


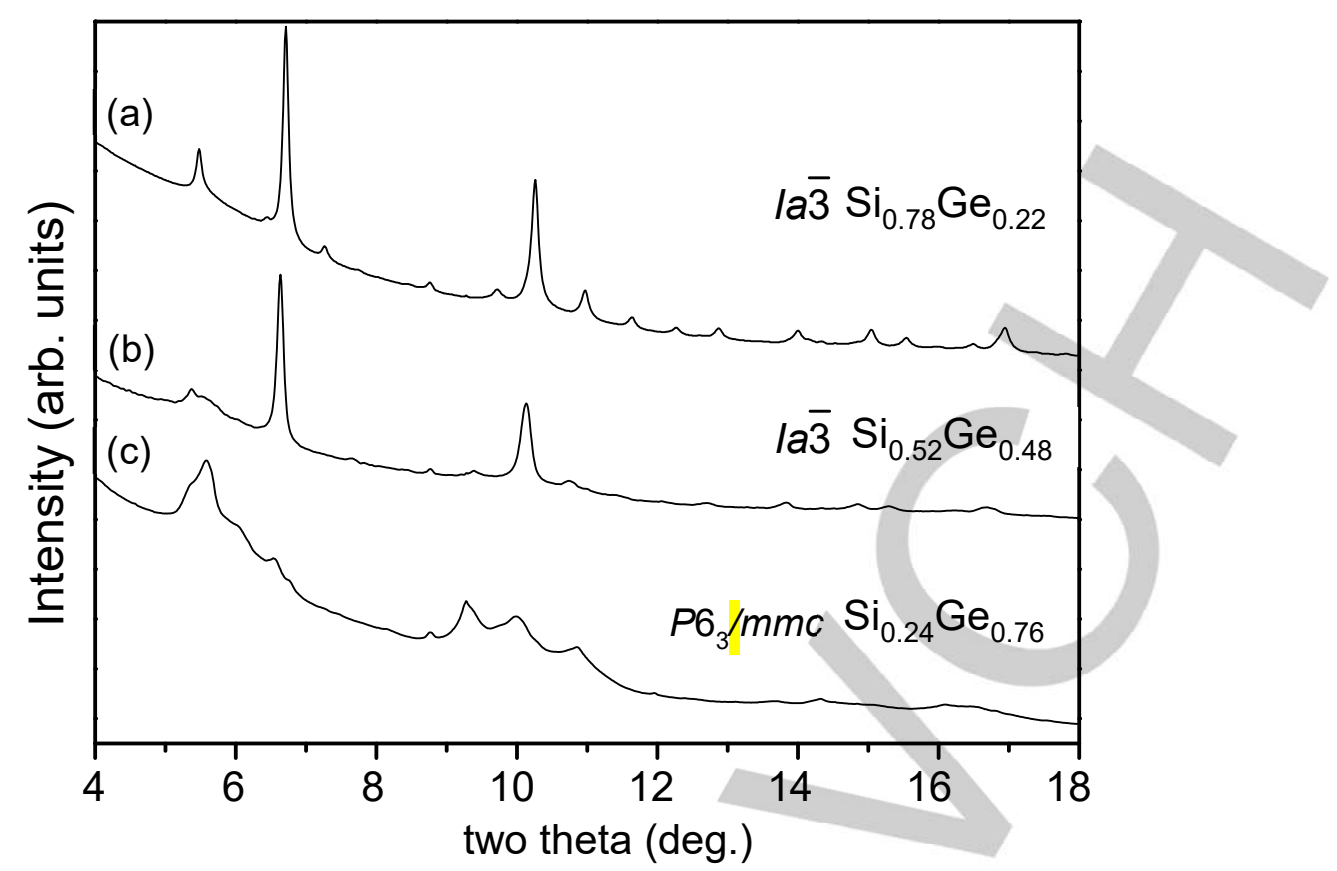

Figure 5. X-ray diffraction patterns of Ge-Si solid solutions of three different bulk compositions recovered to ambient conditions from high pressures and temperatures. (a) X-ray diffraction pattern of a bulk $\mathrm{Ge}_{0.22} \mathrm{Si}_{0.78}$ composition with la $\overline{3}$ space group recovered from $12 \mathrm{GPa}$ after melting at $1500 \mathrm{~K}$ and annealing at

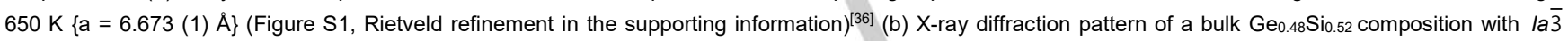
space group recovered from $12 \mathrm{GPa}$ after melting at $1500 \mathrm{~K}$ and annealing at $650 \mathrm{~K}\{\mathrm{a}=6.766$ (1) $\AA$ \} (Figure S2, Rietveld refinement in the supporting information). ${ }^{[36]}$ (c) X-ray diffraction pattern of a bulk $\mathrm{Ge}_{0.76} \mathrm{Si}_{0.24}$ composition with $P 6_{3} / m m c 4 \mathrm{H}$ space group transformed from the la3 symmetry after recovery from $15 \mathrm{GPa}$ after melting there at $1500 \mathrm{~K}\{a=3.916$ (2) $\AA, c=12.980$ (11) $\AA\}$ (Figure S3, Rietveld refinement in the supporting information). ${ }^{[36]}$ Rietveld refinement of $\mathrm{X}$-ray diffraction patterns from further $\mathrm{GeSi}$ reaction products consistent with the $4 \mathrm{H}$ and $8 \mathrm{H}$ polytypes are shown in the supporting information. ${ }^{[36]}$

hexagonal symmetry can also be obtained for $\mathrm{Ge}_{1-\mathrm{x}} \mathrm{Si}_{\mathrm{x}}$ of about $(0.24<x<1.0)$. The existence of the hexagonal $P 6_{3} / \mathrm{mmc}$ phase within the $\mathrm{Ge}_{1-x} \mathrm{Si}_{x}(0<x<1)$ system on recovery from high pressure and temperature, and its relationship to the cubic $l a \overline{3}$ and $P 4_{3} 2_{1} 2$ phases, which can also be recovered, is explained in the discussion section.

\section{Discussion}

Within the $\mathrm{Ge}_{1-x} \mathrm{Si}_{\mathrm{x}}$ system the $P 4_{3} 2_{1} 2$ symmetry can be recovered from multi-anvil experiments for about $(0<x<0.24)$ and the $l a \overline{3}$ symmetry for $x>0.24 .^{[11]}$ It is also known that above 473 $\mathrm{K}$ pure $l a \overline{3} \mathrm{Si}$ transforms to the hexagonal structure $\left(P 6_{3} / m m c\right),{ }^{[21]}$ whereas $P 4_{3} 2_{1} 2 \mathrm{Ge}$ at this temperature transforms directly to the cubic diamond structure $(F d \overline{3} m) \cdot{ }^{[38]}$ In a diamond cell under rapid decompression or hydrostatic conditions pure la $\overline{3} \mathrm{Ge}$ can be fleetingly recovered before it also transforms to the hexagonal structure $\left(P 6_{3} / m m c\right)$ at ambient temperature. ${ }^{[22,30]}$ The principal considerations for why degree of hydrostaticity affects which symmetry is recovered in $\mathrm{Ge}$, and the paths to formation of the hexagonal phase for all Ge-Si compositions are provided below.

Ge $P 4_{3} 2{ }_{1} 2$ and $\mathrm{Si} l a \overline{3}$ are comprised of tetrahedral units, as is their lowest energy but kinetically inaccessible cubic diamond $F d \overline{3} m$ counterpart. ${ }^{[39-40]} P 4_{3} 2_{1} 2$ allows for a greater proximity of its bond lengths to that of $F d \overline{3} m$ at the cost of greater tetrahedral bond angle distortions. Conversely, la $\overline{3}$, allows for smaller tetrahedral bond angle distortions at the cost of greater deviation of the bond lengths from those in the $F d \overline{3} m$ diamond phase. ${ }^{[41-42]} \mathrm{Ge}$ adopts the tetragonal structure $\left(P_{4} 2_{2} 2\right)$ because the $\mathrm{Ge}$ bonds are less stiff than those of $\mathrm{Si}$ (vibrational frequencies are lower than in $\mathrm{Si}$ ). Hence its structure can, under less hydrostatic decompression, accommodate greater angular distortions with relative ease, benefiting on the other hand from bond lengths closer to those of $F d \overline{3} m$ diamond. Conversely under hydrostatic decompression, the $\mathrm{Ge}$ bonds are not distorted and $\mathrm{Ge}$ has no problem to, and indeed adopts the la $\overline{3}$ symmetry on pressure release. The Si bonds on the other hand are stiff, requiring the structure to remain relatively undistorted regardless of hydrostaticity, at the expense however, of a greater distribution of bond lengths with respect to those in $F d \overline{3} m$ diamond. Hence, on recovery, Si, unlike Ge, adopts the la $\overline{3}$ symmetry regardless of the degree of hydrostaticity present.

Why does the hexagonal phase form and what are the concomitant paths to recovery of this phase for $\mathrm{Ge}_{1-x} \mathrm{Si}_{x}$ $(0<x<1)$ ? The hexagonal symmetry has tetrahedra that are close to undistorted and with marginal bond length deviations. They are the most proximal to the perfectly symmetric ones in $F d \overline{3} m{ }^{[41]}$ Indeed, at ambient pressure the hexagonal phase is closest energetically (internal energy, enthalpy) to the lowest energy $F d \overline{3} m$ symmetry. ${ }^{[12]}$ The cubic structure ( la $\overline{3}$ ), unlike the $P 4_{3} 2_{1} 2$ one, has a topological relationship with the energetically more favorable hexagonal structure, making the la $\overline{3}$ to $P 6_{3} / m m c$ transformation accessible, albeit with some 


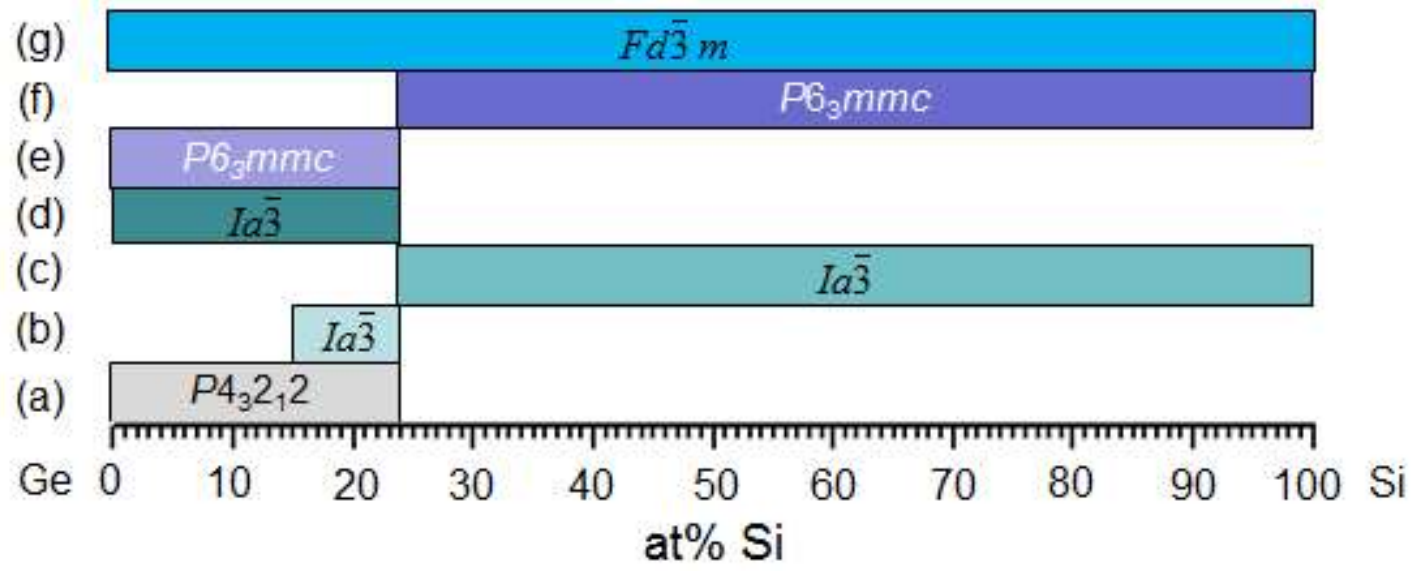

Figure 6. Formation path and schematic depiction of phase relations in the $\mathrm{Ge}_{1-\mathrm{x}} \mathrm{Si}_{\mathrm{x}}$ system at ambient pressure. (a) For $0<\mathrm{x}<0.24$, the tetragonal $P 4_{3} 2_{1} 2$ symmetry is recovered after heating $\mathrm{Ge}$ and $\mathrm{Si}$ at and above $10 \mathrm{GPa}$ under less hydrostatic decompression, and is stable indefinitely at ambient pressure and temperature. (b) For $0.15<\mathrm{x}<0.24$, the cubic la3 symmetry can also be recovered after heating $\mathrm{Ge}$ and $\mathrm{Si}$ at and above $10 \mathrm{GPa}$ under less hydrostatic decompression, but it only has a fleeting stability at ambient pressure and temperature. (c) For $0.24<x<1$, the cubic structure ( la $\overline{3}$ ) is recovered after heating Ge and $\mathrm{Si}$ at and above $10 \mathrm{GPa}$ under hydrostatic as well as under less hydrostatic decompression and is stable indefinitely at ambient temperature and pressure. (d) For $0<x<0.24$, the cubic structure ( $1 a \overline{3}$ ) is recovered after heating $\mathrm{Ge}$ and $\mathrm{Si}$ at and above $10 \mathrm{GPa}$ under hydrostatic conditions and is only fleetingly stable at ambient pressure and temperature. (e) For $0<x<0.24$, the $P 6_{3} / m m c$ symmetry is formed rapidly from the recovered cubic phase (la $\overline{3}$ ) at ambient pressure and temperature and is stable indefinitely at ambient pressure and temperature. (f) For $0.24<x<1$, the $P 6_{3} / m m c$ symmetry is formed from the recovered cubic phase ( $l a \overline{3}$ ) after heating at ambient pressure and is stable indefinitely at ambient pressure and temperature. (g) For $0<x<1$, the cubic $F d \overline{3} m$ symmetry is formed upon heating $\mathrm{Si}$ and $\mathrm{Ge}$ at pressures from ambient to $9 \mathrm{GPa}$ and also upon heating the tetragonal phase $\left(P 4_{3} 2_{1} 2\right)$ and the hexagonal phase $P 6_{3} / m m c$.

(a) $\quad \mathrm{Ge}_{1-\mathrm{x}} \mathrm{Si}_{\mathrm{x}} 0<\mathrm{x}<1$

(b) $\mathrm{Ge}_{1-\mathrm{x}} \mathrm{Si}_{\mathrm{x}} 0<\mathrm{x}<1$

(c) $\mathrm{Ge}_{1-x} \mathrm{Si}_{x} 0<x<0.24$
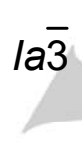

$P 6_{3} / m m c$

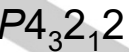

\section{$298 \mathrm{~K}<\mathrm{T}<473 \mathrm{~K}$}

$1 \mathrm{~atm}$

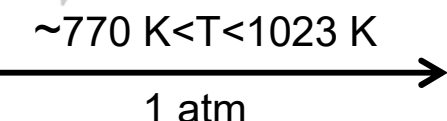

$F d \overline{3} m$

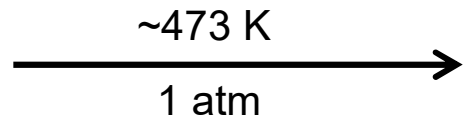

$P 6_{3} / m m c$

Figure 7. Schematic of ambient pressure transformation temperatures between different $\mathrm{Ge}_{1-x} \mathrm{Si}_{x}$ phases. (a) $\mathrm{Ge}-\mathrm{Si} l a \overline{3}$ transition temperatures to $P 6_{3} / m m c$ with $\mathrm{T}$ increasing from $298 \mathrm{~K}$ above $\mathrm{x}=0.24$. (b) Ge-Si $P 6_{3} / m m c$ transformation temperatures to $F d \overline{3} m$ with $\mathrm{T}$ increasing with $\mathrm{x}$. (c) Ge-Si $P 4{ }_{3} 2{ }_{1} 2$ transformation temperature to $\mathrm{Fd} \overline{3} \mathrm{~m}$ with $\mathrm{T}$ likely decreasing with $\mathrm{x}$ because pure Si $P 4_{3} 2,2$ cannot be made using static compression methods.

bond reconstruction. ${ }^{[43]}$ la $\overline{3}$ is hence the symmetry from which $P 6_{3} / m m c$ forms. When then do we recover the la $\overline{3}$ symmetry, and what conditions are required to access the $P 6_{3} / m m c$ symmetry from it? The kinetic barrier between pure Ge la 3 , with its more accommodating weaker bonds, and the hexagonal symmetry is lower than for $\mathrm{Si} l a \overline{3}$. This is consistent with the fact that the transition of $\mathrm{Ge} / \mathrm{a} \overline{3}$ to $P 6_{3} / \mathrm{mmc}$ takes place at ambient temperature on recovery. ${ }^{[22]} \mathrm{Si} / \mathrm{a} \overline{3}$ on the other hand is stable indefinitely at ambient temperature. ${ }^{[21]}$ Thus the more $\mathrm{Si}$ that is incorporated into the GeSi solid solution, the more stable the recovered $l a \overline{3}$ symmetry becomes. We have detected in our multi-anvil data (cumulative electron and X-ray diffraction assessment) without further ambient pressure heating, both the $P 6_{3} / m m c$ and the $P 4_{3} 2_{1} 2$ symmetry in $\mathrm{Ge}_{1-x} \mathrm{Si}_{x}$ for about $0.15<x<0.24 \mathrm{Si}$. Thus up to at least $\mathrm{Ge}_{0.76} \mathrm{Si}_{0.24}$, recovery in the la $\overline{3}$ symmetry will result in conversion to the $P 6_{3} m m c$ symmetry at room temperature, whereas for $0.24<x<1$, higher temperatures not exceeding about $473 \mathrm{~K}$ may be required for transformation of $l a \overline{3}$ to the hexagonal phase. Under hydrostatic conditions then, for $\mathrm{Ge}_{1-x} \mathrm{Si}_{\mathrm{x}}$, where the $l a \overline{3}$ symmetry is recovered for all $\mathrm{x}, P 6_{3} / \mathrm{mmc}$ will form at room temperature for $0<x<0.24$ and will only require heating up to $473 \mathrm{~K}$ for larger $\mathrm{x}$ Under less hydrostatic conditions the $P 4_{3} 2_{1} 2$ symmetry will be recovered for $0<x<0.24$ and the $l a \overline{3}$ symmetry will overlap for $0.15<x<0.24$. Again, for $0.15<x<0.24$ the $l a \overline{3}$ phase will convert to the $P 6_{3} m m c$ symmetry at room temperature and at temperatures up to $473 \mathrm{~K}$ for $\mathrm{x}>0.24 . \mathrm{Ge}_{1-\mathrm{x}} \mathrm{Si}_{\mathrm{x}} \quad P_{4} 4_{3} 2$ for all recovered compositions $(0<x<0.24)$ at about $473 \mathrm{~K}$ transforms directly to $\mathrm{Fd} \overline{3} \mathrm{~m}$. $P 6_{3} / \mathrm{mmc} \mathrm{Si}$ requires about $1000 \mathrm{~K}$ to transform to $F d \overline{3} m$. These phase relations are depicted schematically in Figures 6 and 7 .

\section{Conclusion}


The promise, pace of development and investment in binary group IV alloys to push the limitations of the endmembers back is substantial. ${ }^{[31,44]}$ Tunability, higher processing speeds, greater storage capacity in smaller sizes and more efficient light conversion drive this investment. Diamond structured group IV alloys are still the dominant material focus, not least because they are robust, but also familiar. New crystal classes can offer these features, as well as enhanced attributes. Namely, the current new hexagonal class has a structural arrangement with near perfect tetrahedra resembling those in the diamond structure and with likely high thermal stability due to silicon incorporation in the structure. Enhanced light conversion in this semiconducting hexagonal class with respect to the $F d \overline{3} m$ symmetry is a particularly strong attribute, due to the direct band-gap of hexagonal $\mathrm{Ge}\left(P 6_{3} / \mathrm{mmc}\right) \cdot{ }^{[12,31]}$

Moreover this work offers a chemical solution to a pressing engineering problem. ${ }^{[31,45]}$ Namely to produce hexagonal SiGe, that is un-templated, rid of substrate attachments in order to be able to develop optoelectronic devices with pure hex-SiGe and $\mathrm{Si}$ integrated on the same chip. We produce here pure and bulk hexagonal SiGe. Moreover, the ability to prepare different polytypes $^{[36]}$ and tune the band-gap with stacking sequence ${ }^{[34]}$ as well, affords further tailoring of optoelectronic properties.

Fundamentally the work also illustrates the in-concert methods by which we can explore and prepare desired structures and properties. Pressure and temperature can allow us to form structures from which new solid solutions can be recovered. Degree of isotropicity of the pressure profile as well as compositional content can be used to select which structure is recovered. The work also illustrates the complementary importance of large volume and diamond cell methods, precession electron diffraction specifically, and X-ray diffraction methods for respectively synthesis and investigation of structural transformations. In this vein it should be noted that as dynamic methods including pulsed lasers and shock methods in conjunction with in-situ XFEL (X-ray free-electron lasers), are incorporated in the repertoire of perturbation and characterization tools for exploring and preparing new materials landscapes, precession electron diffraction will become even more important in investigating increasingly complex recovered agglomerates with highest spatial resolution and kinematic intensities in order to effectively identify and map new materials landscapes.

\section{Experimental Section}

We employed ultrapure Ge pieces $(99.9999+\%$ puratronic Alfa Aesar) and Si pieces (99.999 metal basis \% Alfa Aesar) as starting materials. Nine multi-anvil experiments and two laser heated diamond anvil cell experiments were performed. For the multi-anvil experiments $\mathrm{Ge}: \mathrm{Si}$ mixtures were placed in rhenium or lidded aluminum oxide crucibles. Three experiments were done at $12 \mathrm{GPa}$, two at $13 \mathrm{GPa}$, two at $15 \mathrm{GPa}$ and two at $17 \mathrm{GPa}$. The two $15 \mathrm{GPa}$ multi-anvil experiments were performed at the Bavarian Research Institute of Experimental Geochemistry and Geophysics in Bayreuth and the seven others at the German Research Centre for Geosciences in Potsdam. For the experiments at 12 and $13 \mathrm{GPa}, 14 / 8$ assemblies (octahedral length/truncation length) were used with a Cr-doped MgO-based octahedron serving as a pressure transmitting medium and the $17 \mathrm{GPa}$ experiments were performed with a 10/5-assembly, which was calibrated using the following phase transitions: coesite-stishovite, $\alpha-\beta \mathrm{Mg}_{2} \mathrm{SiO}_{4}$, $\beta-\gamma \mathrm{Mg}_{2} \mathrm{SiO}_{4}$, enstatite- $\beta-\mathrm{Mg}_{2} \mathrm{SiO}_{4}$-stishovite. ${ }^{[46]}$ In these experiments stepped graphite heaters were employed and temperatures were measured with type $C$ thermocouples $\left(\mathrm{W}_{95} \mathrm{Re}_{5} / \mathrm{W}_{74} \mathrm{Re}_{26}\right)$, with emf's uncorrected for pressure. The two $15 \mathrm{GPa}$ experiments were performed using a Sumitomo hydraulic press employing $18 / 11$ and 10/5 assemblies (octahedral length/ truncations length) respectively with a Cr-doped $\mathrm{MgO}$ octahedron serving as a pressure transmitting medium. A stepped $\mathrm{LaCrO}_{3}$ heater was employed and temperatures were measured using a $W_{97} R_{3} / W_{75} R_{25}$ thermocouple (type $\quad D$ ) with electromotive forces uncorrected for pressure. Pressure calibration was performed using a number of high pressure-ambient and high pressure-high temperature phase transformations. These and further experimental details are discussed in previous work. ${ }^{[47]}$

At $12 \mathrm{GPa} 80: 20,50: 50$ and 20:80 at\% Ge:Si mixtures respectively were melted at 1525,1500 and $1500 \mathrm{~K}$ respectively for 2 minutes followed by annealing at $650 \mathrm{~K}$ for 1 hour before temperature and then pressure quenching. At $13 \mathrm{GPa} 75: 25$ and $40: 60$ at $\%$ Ge:Si mixtures, respectively, were melted at $1500 \mathrm{~K}$ for 2 minutes followed by annealing at $650 \mathrm{~K}$ for 2 hours before temperature and then pressure quenching. At $15 \mathrm{GPa} 80: 20 \mathrm{Ge}: \mathrm{Si}$ mixtures were melted at $1500 \mathrm{~K}$ for 2 minutes followed by quenching to room temperature in about 20 minutes, followed by pressure release. At $17 \mathrm{GPa} 75: 25$ and $60: 40$ at\% Ge:Si mixtures respectively were melted at $1473 \mathrm{~K}$ for 2 minutes followed by annealing at $800 \mathrm{~K}$ for 2 hours before temperature and then pressure quenching. For the two laser-heated diamond anvil cell experiments, pressed pellets nominally containing approximately 80 atom $\% \mathrm{Ge}, 20$ atom $\% \mathrm{Si}$ and 20 atom $\% \mathrm{Ge}, 80$ atom $\%$ Si respectively were placed on 3 micron polished $\mathrm{Al}_{2} \mathrm{O}_{3}$ plates to prevent any reaction with the bottom anvil. These were placed in the middle of 140 micron, laser-drilled, pre-indented tungsten gasket holes which were filled with an argon pressure and reactive medium using a $3 \mathrm{kbar}$ gas loader at the Max-Planck Institute for Chemistry in Mainz. Pressure was measured using micron sized rubies placed close to the pressed pellets. ${ }^{[48]}$ Laser-heating was performed using a fiber-pumped 110 watt ytterbium-glass, single-mode continuous wave $1070 \mathrm{~nm}$ laser. Temperatures were measured using a Planck radiation function. ${ }^{[49]}$ The samples were compressed to 12 and $13 \mathrm{GPa}$ and heated for about 1- 2 minutes followed by temperature quenching and subsequent release of pressure.

The samples were polished and carbon coated for electron microscopy measurements. Scanning Electron Microscopy (Philips XL30CP, with an Energy Dispersive X-ray (EDX) analyser (Oxford instruments EDX detector - SiLi crystal with PGT spirit analysis software)) was employed for chemical and morphological analysis from the polished pellets. The acceleration voltage used was set to $20 \mathrm{kV}$. Backscattered electron mode was primarily used because it allows for chemical contrast. ${ }^{[50]}$ Samples were also investigated with a Philips CM30, Transmission Electron Microscope (TEM), equipped with a $1 \mathrm{kx}$ 1k Gatan slow scan CCD camera and with Digital Micrograph software for acquisition of electron diffraction patterns and bright-field imaging with an accelerating voltage of $300 \mathrm{kV}$. The CM30 is also equipped with a Nanomegas "Spinning Star" precession system and a Noran EDX detector for local chemical analysis. The camera length for TEM was calibrated using pure silicon. Semi-quantitative chemical analysis was carried out without standards for the determination of the Cliff-Lorimer factors and without measurement of local thin foil thickness. Precession electron diffraction (PED) measurements were performed in microdiffraction mode, i.e. with a nearly parallel incident beam focused on the specimen with a spot size in the range of 10 to $50 \mathrm{~nm}$. The precession semi-angle of $2^{\circ}$ was set to record PED patterns. The maximum precession angle of about $3^{\circ}$ was systematically used in order to further identify the kinematically forbidden reflections. ${ }^{[51-53]}$ PED performed at a high precession semi-angle of $\geq 2^{\circ}$ in particular, significantly reduces the overall dynamical effects involved in an electron diffraction pattern, which in turn allows for a drastically improved measurement of kinematical intensities of diffracted reflections from the single crystallites. This facilitates differentiation even between closely related diffraction patterns and concomitant accurate crystallographic indexing of the new phases. ${ }^{[51-58]}$ Angle dispersive X-ray diffraction measurements were performed at the Extreme Conditions Beamline P02.2, PETRA III, DESY and at the ID11 beamline of the European 
Synchrotron Radiation Facility. At P02.2 a monochromatic X-ray beam $(\lambda=0.28928 \AA)$ was focused to $3 \mu \mathrm{m} \times 3 \mu \mathrm{m}$ (FWHM) with KirkpatrickBaez mirrors. A Perkin Elmer XRD1621 was used for diffraction data collection with a pixel size of $200 \times 200 \mu \mathrm{m}$. $\mathrm{CeO}_{2}$ powder (National Institute of Standards SRM 674b), was used to calibrate the distance and the orientation of the detector. ${ }^{[59]}$ This calibration was cross-checked with Argon diffraction patterns and the equation of state of $\operatorname{Argon}^{[60]}$ also used as a pressure medium in the diamond anvil cell experiments and the pattern wavelength is adapted to $\lambda=0.31849 \AA$, to directly compare to those at ID11 where the latter wavelength was employed. At ID11 a monochromatic X-ray beam $(\lambda=0.31849 \AA)$ was focused to $10 \mu \mathrm{m} \times 7$ $\mu \mathrm{m}$ using a tunable $\mathrm{X}$-ray focusing apparatus (transfocator) containing twenty beryllium lenses and 254 aluminium lenses. ${ }^{[61]}$ A Frelon $4 M$ CCD detector was used for diffraction data collection with a pixel size of $50 \mathrm{x}$ $50 \mu \mathrm{m}$. LaB 6 powder (National Institute of Standards SRM 660a), also placed in a square on a copper grid and on kapton holders, was used to calibrate the distance and orientation of the detector. A Si-fluorescence detector was also installed on ID11 which allowed us to obtain a chemical signature from the very spot from which diffraction was performed. For the electron and X-ray diffraction measurements (on ID11), particles of the reaction product from the polished half capsules were taken under an 126x total magnification optical microscope, using a sharp tungsten carbide needle and dispersed onto the thin carbon film of labelled three millimeter diameter copper TEM grid (Agar scientific). For the X-ray diffraction (on ID11) measurements, particles were also placed on litholoops (Molecular Dimensions Limited). For the X-ray diffraction measurements (at P02.2) particles of the reaction product from the polished half capsules were taken under an 126x total magnification optical microscope, using a sharp tungsten carbide needle and packed in drilled gasket holes which were then sealed between the anvils of a diamond anvil cell. The zone-axis electron diffraction patterns were interpreted using the software "Electron Diffraction" version 7.01 by considering the kinematical approximation. ${ }^{[62]}$ Note that in all the simulated zone-axis diffraction patterns shown hereafter an empty circle represents a kinematically forbidden reflection and the size of a filled circle is proportional to the intensity of the diffracted reflection. Precession electron diffraction provided highest spatial resolution single crystal analysis based both on diffraction spot positions and intensities which allowed us to rigorously differentiate even between closely related structures. The X-ray diffraction patterns were circularly integrated using Fit2 ${ }^{[63]}$ and one-dimensional patterns exhibiting sharp diffraction peaks were fitted and indexed using the Topas 3.0 software. ${ }^{[64]}$ Input lattice, profile and background parameters for Rietveld refinement were from Le Bail whole pattern fitting and input positional parameters were from [27, 65]. The diffraction intensity profiles for this alloy system are not sensitive to occupancy values. Accordingly[66] occupancies for the dominant phase where fixed to those obtained from chemical analysis using our energy dispersive X-ray measurements and for any minority phases from a Vegards estimation based on Le Bail fitted parameters. The chemical signatures taken from the samples at ID11 in-parallel with the diffraction, was performed using the program PyMCA. ${ }^{[67]}$

\section{Acknowledgements}

We are grateful to Professor Jean-Paul Morniroli for his guidance and support. The TEM facility in Lille (France) is supported by the Conseil Regional du Nord-Pas de Calais and the European Regional Development Fund (ERDF). We also gratefully acknowledge EU I-20110930 at DESY (Deutsches Elektronen-Synchrotron) and MA712 grants for experiments at ESRF (European Radiation Synchrotron Facility) as well as the EU "Research Infrastructures: Transnational Access" Programme (Bayerisches Geoinstitut). We also thank the Moray foundation and the Innovative Initiative grant program for support. We further warmly thank Ahmed Addad for his work and consultation on chemical microanalysis using transmission electron microscopy, Nicola Cayzer for consultation on scanning electron microscopy and Michael Hall for demanding solids processing and Laurence Nigay for consultation on the manuscript. We also thank Paul Johnson and Niall Russell for contributing to component micromanufacture, assembly and characterization as well as Reiner Schulz and Andreas Ebert for their support with the multi-anvil experiments.

Keywords: materials synthesis $\cdot$ reactivity $\cdot$ alloys, solid solutions $\cdot$ high pressure and temperature chemistry• precession electron diffraction and angle dispersive $\mathrm{X}$-ray diffraction

[1] a) M. S. Hybertsen, S. G. Louie, Phys. Rev. B 1986, 34, 5390-5413; b) R. Braunstein, A. R. Moore, F. Herman, Phys. Rev. B 1958, 109, 695 710.

[2] a) S. G. Cloutier, P. A. Kossyrev, J. Xu, Nat. Mat. 2005, 4, 887-891 b) Y. H. Kuo, Y. K. Lee, Y. S. Ge, S. Ren, J. E. Roth, T. I. Kamins, D. A. B. Miller, J. S. Harris, Nature 2005, 437, 1334-1336; c) N. Q. Vinh N. N. Ha, T. Gregorkiewicz, Proc. of the IEEE 2009, 97, 1269-1283; d) S. Adachi, M. Oi, J. Appl. Phys. 2007, 102, 063506-063515, e) J. Liu, X. Sun, D. Pan, X. Wang, L. C. Kimerling, T. L. Koch, J. Michel, Opt. Expr. 2007, 15, 11272-11277; f) A. E. Vasdekis, S. A. Moore, A Ruseckas, T. F. Krauss, I. D. W. Samuel, G. A. Turnbull, Appl. Phys Lett. 2007, 91, 051124-051127.

[3] a) D. A. Young, Phase Diagrams of the Elements; $1^{\text {st }}$ ed.; University of California Press: Berkeley, 1991; b) A. Mujica, A. Rubio, A. Munoz, R. J. Needs, Rev. Mod. Phys. 2003, 75, 863-912; c) F. P. Bundy, J. Chem Phys. 1964, 41, 3809-3814; d) J. P. Dismukes, R. J. Paff, L. Ekstrom, J. Phys. Chem. 1964, 68, 3021-3027; e) J. C. Jamieson, Science 1963 139, 762-764; e) Y. K. Vohra, K. E. Brister, S. Desrgeniers, A. L. Ruoff, K. J. Chang, M. L. Cohen, Phys. Rev. Lett. 1986, 56, 1944-1947, f) R. J. Nelmes, H. Liu, S. A. Belmonte, J. S. Loveday, M. I. McMahon, D. R. Allan, D. Hausermann, M. Hanfland, Phys. Rev. B 1996, 53, R2907R2909; g) M. I. McMahon, R. J. Nelmes, N. G. Wright, D. R. Allan, Phys. Rev. B 1994, 50, 739-743; h) S. P. Lewis, M. L. Cohen, Phys Rev. B 1993, 48, 16144-16147; (h) M. Hanfland, U. Schwarz, K. Syassen, K. Takemura, Phys. Rev. Lett. 1999, 82, 1197-1200; i) J. Z. Hu, L. D. Merkle, C. S. Menoni, I. L. Spain, Phys. Rev. B 1986, 34 4679-4684; j) K. J. Chang, Phys. Rev. B 1986, 34, 8581-8590. k) A. D Cicco, A. C. Frasini, M. Minicucci, E. Principi, J. P. Itie, P. Munsch, Phys. Stat. Solidi B-Basic Res. 2003, 240, 19-28; I) H. J. Mcskimin, P. Andreatch, J. Appl. Phys. 1964, 35, 2161-2165; m) K. Gaal-Nagy, D. Strauch, Comput. Mat. Sci. 2004, 30, 8-15.

[4] a) V. Prakapenka, A. Kubo, A. Kuznetsov, A. Laskin, O. Shkurikhin, P Dera, M. L. Rivers, S. R. Sutton, High Pressure Res. 2008, 28, $225-$ 235; b) A. Kubo, Y. Wang, C. E. Runge, T. Uchida, B. Kiefer, N. Nishiyama, T. S. Duffy, J. Phys. Chem. Solids 2008, 69, 2255-2260; c) G. A. Voronin, C. Pantea, T. W. Zerda, J. Zhang, L. Wang, Y. Zhao, Phys. Rev. B, 2003, 68, 020102R.

[5] G. Serghiou, N. Odling, R. Hunter, A. Abbie, B. Armstrong, C. Lathe High Pressure Res. 2014, 34, 176-183.

[6] S. Wirths, R. Geiger, N. von den Driesch, G. Mussler, T. Stoica, S. Mantl, Z. Ikonic, M. Luysberg, S. Chiussi, J. M. Hartmann, H. Sigg, J. Faist, D. Buca, D. Grutzmacher, Nature Photonics 2015, 9, 88-92.

[7] K. P. Homewood, M. A. Lourenco, Nature Photonics 2015, 9, 78-79.

[8] C. Guillaume, G. Serghiou, A. Thomson, J. P. Morniroli, D. J. Frost, N Odling, M. Mezouar, J. Am. Chem. Soc. 2009, 131, 7550-7551.

[9] C. L. Guillaume, G. Serghiou, A. Thomson, J. P. Morniroli, D. J. Frost, N. Odling, C. E. Jeffree, Inorg. Chem. 2010, 49, 8230-8236.

[10] G. Serghiou, C. L. Guillaume, C. E. Jeffree, A. Thomson, D. J. Frost, J. P. Morniroli, N. Odling, High Pressure Res. 2010, 30, 44-50.

[11] G. Serghiou, G. Ji, M. Koch-Müller, N. Odling, H. J. Reichmann, J. P. Wright, P. Johnson, Inorg. Chem. 2014, 53, 5656-5662.

[12] B. D. Malone, M. L. Cohen, Phys. Rev. B. 2012, 86, 054101

[13] F. Kieffer, V. Hlukhyy, A. J. Karttunen, T. F. Fässler, C. Gold, E. W. Scheidt, W. Scherer, J. Nylen, U. Hausermann, J. Mater. Chem. 2010, 20, 1780-1786. 
[14] H. I. T. Hauge, M. A. Verheijen, S. Conesa-Boj, T. Etzelstorfer, M. Watzinger, D. Kriegner, I. Zardo, C. Fasolato, F. Capitani, P. Postorino, S. Kolling, A. Li, S. Assali, J. Stangl, E. P. Bakkers, Nano Lett. 2015, 15 5855-5860.

[15] A. De, C. E. Pryor, J. Phys. Cond. Matt. 2014, 26, 055801.

[16] J. D. Joannopoulos, M. L. Cohen, Phys. Rev. B 1973, 7, 2644-2657.

[17] C. Rödl, T. Sander, F. Bechstedt, J. Vidal, P. Olsson, S. Laribi, J. F. Guillemoles, Phys.Rev. B 2015, 92, 045207.

[18] S. Q. Wang, H. Q. Ye, J. Phys. Cond. Matt. 2003, 15, 5307-5314.

[19] S. Q. Wang, H. Q. Ye, J. Phys Cond Matt 2003, 15, L197-L202.

[20] B. D. Malone, J. D. Sau, M. L. Cohen, Phys. Rev. B 2008, 78, 035210.

[21] R. H. Wentorf, J. S. Kasper, Science 1963, 139, 338-339.

[22] R. J. Nelmes, M. I. McMahon, N. G. Wright, D. R. Allan, J. S. Loveday, Phys. Rev. B 1993, 48, 9883-9886.

[23] B. Haberl, M. Guthrie, S. V. Sinogeikin, G. Y. Shen, J. S. Williams, J. E. Bradby, High Pr. Res. 2015, 35, 99-116.

[24] V. V. Brazhkin, A. G. Lyapin, S. V. Popova, R. N. Voloshin, JETP Lett. 1992, 56, 152-156.

[25] L. Vincent, G. Patriarche, G. Hallais, C. Renard, C. Gardes, D. Troadec, D. Bouchier, Nano Lett. 2014, 14, 4828-4836

[26] S. Pandolfi, C. Renecuro-Lecuna, Y. Le Godec, B. Baptiste, N Menguy, N.; Lazzeri, M.; Gervais, C.; Spektor, K.; Crichton, W. A. and O. O. Kurakevych, Nano Lett. 2018, 18, 5989-5995.

[27] J. S. Kasper, S. M. Richards, Acta Crystallogr. 1964, 17, 752-755.

[28] S. Minomura, J. de Physique 1981, 42, 181-188.

[29] A. Wosylus, H. Rosner, W. Schnelle, U. Schwarz, Zeitschrift fur Anorganische und Allgemeine Chemie 2009, 635, 700-703.

[30] B. Haberl, M. Guthrie, B. D. Malone, J. S. Smith, S. V. Sinogekin, M. L. Cohen, J. S. Williams, G. Y. Shen, J. E. Bradby, Phys. Rev. B 2014 89, 144111.

[31] E. M. T. Fadaly, A. Dijkstra, J. R. Suckert, D. Ziss, M. A. J. van Tilburg, C. Y. Mao, Y. Z. Ren, V. T. van Lange, K. Korzun, S. Kolling, M. A. Verheijen, M. A.; D. Busse, C. Roedl, J. Furthmueller, F. Bechstedt, J. Stangl, J. J. Finley, S. Botti, J. E. M. Haverkort, E. P. A. M. Bakkers Nature 2020, 580, 202-228.

[32] A. Fissel, E. Bugiel, C. R. Wang, H. J. Osten, Mat. Sci. and EngB. 2006 134, 138-141.

[33] C. Persson, E Janzen, J. Phys Cond Matt 1998, 10 , 10549-10555.

[34] C. Raffy, J. Furthmuller, F. Bechstedt, Phys. Rev. B 2002, 66, 075201

[35] a) G. Serghiou, G. Ji, N. Odling, H. J. Reichmann, J. P. Morniroli, R. Boehler, D. J. Frost, J. P. Wright, B. Wunder, Angew. Chem. Int. Ed. 2015, 54, 15109-15112; b) G. Serghiou, G. Ji, N. Odling, H. J. Reichmann, D. J. Frost, J. P. Wright, High Pressure Res. 2015, 35, 2836.

[36] Supporting information

[37] M. M. Treacy, J. M. Newsam, M. W. Deem, Proc. R. Soc. Lond. A 1991, 433, 499-520.

[38] F. P. Bundy, J. S. Kasper, 1963, 139, 340-341.

[39] G. J. Ackland, Progress in Physics 2001, 64, 483-516.

[40] J-T. Wang, C. Chen, H. Mizuseki, Y. Kawazoe, Phys. Rev. Lett. 2013 110, 165503-166508.

[41] S. J. Clark, G. J. Ackland, J. Crain, Phys. Rev. B 1994, 49, 5341-5352

[42] J. Crain, G. J. Ackland, S. J. Clark, Rep. Prog. Phys. 1995, 58, 705754

[43] a) H. Katzke, U. Bismayer, P. Toledano, Phys. Rev. B 2006, 73, 134105.

b) R. Biswas, R. M. Martin, R. J. Needs, O. H. Nielsen, Phys. Rev. B 1987, 35, 9559-9568

[44] a) C. G. Littlejohns, M. Nedeljkovic, C. F. Mallinson, J. F.Watts, G. Z. Mashanovich, G. T. Reed, F. Y. Gardes, Scientific Reports 2015, 5, 8288; b) G. Serghiou, H. J. Reichmann, N. Odling, K. Spektor, A. Pakhomova, A., W. Crichton, Z. Konôpková, Angew. Chem. Ed. 2021, 60, 9009-9014; c) A. Elbaz, D. Buca, N. von der Driesch, K. Pantzas, G. Patriarche, N. Zerounian, E. Herth, X. Checoury, S. Sauvage, I. Sagnes, A. Foti, R. Ossikovski, J. M. Hartmann, F. Boeuf, Z. Ikonic, P. Boucaud, D. Grutzmancher, M. El Kurdi, Nat. Phot. 2020, 14, 375-382. d) G. Serghiou, N. Odling, H. J. Reichmann, K. Spektor, W. A. Crichton, G. Garbarino, M. Mezouar, A. Pakhomova, J. Am. Chem. Soc. 2021, 143, 7920-7924.; e) J. Wagner, M. NunezValdez, Appl. Phys. Lett. 2020, 117, 032105

[45] D-S. Liu, J. Wu, H. Xu, Z. Wang, Adv. Mater. 2021, 33, 202003733.

[46] a) M. Koch-Müller, D. Rhede, R. Schulz, R., Phys. Chem. Min. 2009, 36, 329-341; b) M. Akaogi, H. Yusa, K. Shiraishi, T. Suzuki, J. Geophys. Res. 1995, 100, $337-347$, c) H. Morishima, T. Kato, M. Suto, E. Ohtani, S. Urakawa, W. Utsumi, O. Shimomura, T. Kikegawa, Science 1994, 26, 1202 - 1203, d) T. Inoue, T. Irifune, Y. Higo, T. Sanehira, Y. Sueda, A. Yamada, T. Shinmei, D. Yamazaki, J. Ando, K. Funakoshi, W. Utsumi, Phys. Chem. Min. 2006, 33, 106-114. e) T. Gasparik, Contr. Min. Petr. 1989, 102, $389-405$.

[47] a) D. J. Frost, B. T. Poe, R. G. Tronnes, C. Liebske, A. Duba, D. C. Rubie, Phys. Earth Plan. Sci. Int., 2004, 143, 507-514; b) H. Keppler, D. $\mathrm{J}$. Frost, EMU notes in Mineralogy 2005, 7, 1-30; c) D. C. Rubie, Phase transitions 1999, 68, 431-451; d) C. Guillaume, J. P. Morniroli, D. J. Frost, G. Serghiou, J. Phys. Cond. Matt. 2006, 18, 8651-8660.

[48] H. K. Mao, P. M. Bell, J. Geophys. Res. Solid Earth 1986, 91, 46734676 .

[49] a) R. Boehler, R. Reviews of Geophysics 2000, 38, 221-245; b) R.
Boehler, H. G. Musshoff, R. Ditz, G. Aquilanti, A. Trapananti, Rev. Sci Instrum. 2009, 80, 045103.

[50] a) J. I. Goldstein, D. .E. Newbury, P. Echlin, Scanning Electron Microscopy and X-ray Microanalysis; Plenum Press, New York, 1992. b) A. J. McGaff, G. Serghiou, D. J. Frost, High Pressure Res. 2008, 28, 491-495.

[51] R. Vincent, P. A. Midgley, Ultramicroscopy 1994, 53, 271-282.

[52] J. P. Morniroli, G. J. Auchterlonie, J. Drennan, J. Zou, J. Microsc. 2008, 232, 7-26.

[53] J. P. Morniroli, G. Ji, Mat. Res. Soc. Symp. Proc. 2009, 1184, 37-48.

[54] G. Ji, J. P. Morniroli, G. J. Aucherlonie, J. Drnnan, D. Jacob, Ultramicroscopy 2009, 109, 1282-1294.

[55] J. P. Morniroli, G. Ji, D. Jacob, Ultramicroscopy 2012, 121, 42-60.

[56] D. Jacob, G. Ji, J. P. Morniroli, Ultramicroscopy 2012, 121, 61-71.

[57] G. Ji, J. P. Morniroli, J. Appl. Cryst. 2013, 46, 430-442

[58] J. Hadermann, A. M. Abakumov, S. Turner, Z. Hafideddine, N. R. Khasanova, E. V. Antipov, G. Van Tendeloo, Chem. Mater. 2011, 23, 3540-3545

[59] H. P. Liermann, Z. Konopkova, W. Morgenroth, K. Glazyrin, J. Bednarcik, E. E. McBride, S. Petitgirard, J. T. Delitz, M. Wendt, Y. Bican, A. Ehnes, I. Schwank, A. Rothkirch, M. Tischer, J. Heuer, H. Schulte-Schrepping, T. Kracht, H. Franz, J. Synchr. Rad. 2015, 22 908-924.

[60] D. Errandonea, R. Boehler, S Japel, Phys. Rev. B 2006, 73, 092106.

[61] G. B. M. Vaughan, J. P. Wright, A. Bytchkov, H. Rossat, I. Gleyzolle, I. Snigireva, A. Snigirev, J. Synchr. Radiat. 2011, 30, 125-133.

[62] J. P. Morniroli, Electron Diffraction 7.01 LMPGM UMR CNRS 8517 France, 2004

[63] A. P. Hammersley, S. O. Svensson, M. Hanfland, A. N. Fitch, D. Hausermann, High Pressure Res. 1996, 14, 235-248.

[64] Bruker AXS, TOPAS (Bruker AXS inc, Karlsruhe, Germany, 2006)

[65] P. D. Ownby, X. Yang, J. Liu, J. Am. Ceram. Soc. 1992, 75, 1876-1883.

[66] L. B. McCusker, R. B. Von Dreele, D. E. Cox, D. Louer, P. Scardi, J. Appl. Cryst. 1999, 32, 36-50.

[67] V. A. Solé, E. Papillon, M. Cotte, P. Walter, J. A. Susini, Spectrochim. Acta Part B 2007, 62, 63-68. 


\section{Entry for the Table of Contents}
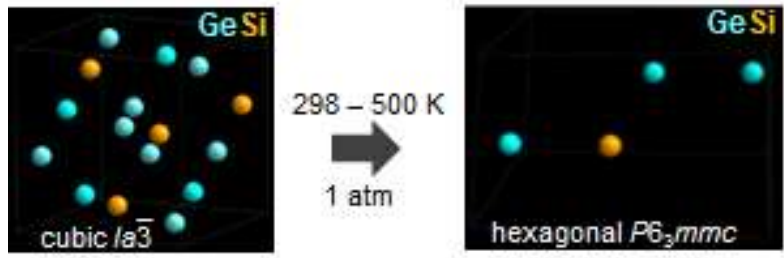

Cubic diamond $(F d \overline{3} m$ ) silicon has been the material driver for electronics from the onset. In that structure however it absorbs and emits light inefficiently and offers no compositional tunability of properties. We address both issues here by creating bulk GeSi solid solutions using pressure which are recovered in a different cubic structure ( la $\overline{3})$. This structure now transforms to a tunable hexagonal one which may not suffer from silicon's deficiencies. 